\title{
Socially Oriented Projects in High Technology Production: The Content and Features of Arrangements and Management
}

\author{
Artem Yu. Pavlov \\ Alexander A. Koretsky \\ Southern Federal University \\ Email: pavlov.tti@gmail.com
}

Doi:10.5901/mjss.2015.v6n3s4p179

\begin{abstract}
The features of arrangements of socially oriented high-technology projects are considered in the article. Have been analyzed and identified the main industry in which to develop high-tech projects. Presented the detailed analysis of environmental factors affecting the company. Describes the main relationship of the enterprise with the external environment. A list of decisions in which support can be innovative community-oriented project of the company are presented. Identified the main directions of socially-oriented projects in high-tech manufacturing, which include medicine, education, environment and infrastructure. The factors that affect the success of the project are described, the main factors - a sign of the industry, the direction of the project, the principles of organization of production, the existing database development regulations, the current management system, the composition of the staff and its qualifications, project financing, part of the state, the impact of competition. Presented enlarged mechanism for managing business processes in high-tech enterprise with the features of the project. This mechanism involves interaction of the following business processes: business process engineering management, business process production management, business process management product implementation, business process marketing analysis, business process software, blocks of information security management and risk management. Presented the main risks associated with the production and sale of products. Examined the components of the security subsystem information.
\end{abstract}

Keywords: high-technology projects, socially oriented projects, business processes controlling mechanism, external environment of the enterprise, research and development.

The present stage of economic relations development is characterized by high speed of changes occurring, and that is, first of all, caused by development of technological constituent. Already now it is possible with confidence to say that the development of high technology productions determines a success of development not just of separate enterprises, segments, regions, but also sets a vector of development of industrial production in most important strategic industries of the country national economy in general.

In this connection the importance increases in correct determination of implementable projects directions and their efficiency assessment. Let's consider which tendencies are observed recently and allocate the most perspective of them.

First of all, we will describe what will be understood as high technology production from our point of view.

Proceeding from the set of works, let's choose the very definition that most suits the modern situation. I.e. as the advanced technology production is understood the production which specializes on release of innovative products competitive in the world and national market, having a high share of added cost in which the latest technologies, hightech methods, processes and means of production are used. (Turko D.A., 2013).

Among the main directions of development it is possible to eliminate those consecutive: (European Communities, 2008):

- the aerospace;

- the radio-electronic, production of COMPUTER and electronic components, office equipment and software (SW), and the industry of communication means as well;

- the medical equipment, precision and optical-electronic equipment;

- the chemical and pharmaceutical.

Thereat as high-technological industries traditionally consider those with share of 4,5-5\%, and as high-knowledgeintensive industries where this share - is higher than $10 \%$ (Washington: NSA, 2010).

It should be noted that more than $60 \%$ of production of high-technology medical equipment in Russian industry, the release of practically all precision and optical-electronic equipment, as well as a number of productions of chemical 
and pharmaceutical, microbiological and chemical industries and scientific instrumentation are concentrated in defensive industries (defense industry complex - DIC)(Frolov I.E., 2011).

Ipso facto, it is possible to say that the development of these industries directly depends on extent of inclusion and realization of innovative projects in these directions.

However, in modern conditions the social orientation of implementable projects starts to play an escalating role. First of all, let's note that as the socially oriented project we will understood the innovative project on release of hightechnology products the same time directed on creation, accretion and up keeping of society social potential. The effect from realization of such projects is often shows up not only by direct impact, but also mediately, through the influence of some indirect factors that further can bear a multiplicative result at project group of direction development of any type of elaborations.

The importance of such projects consists also in that they touch upon quite extensive areas of social sphere and as a result can exert influence, not just at individual level, on group of people, but also on the development of specific region or society as a whole.

For more detailed analysis and identification of factors, influencing on the development and project implementation, and also identifications of key points of potential development of research, let's consider more particularly the possible directions of socially oriented projects in high technology production and interrelation with external environment (fig. 1).

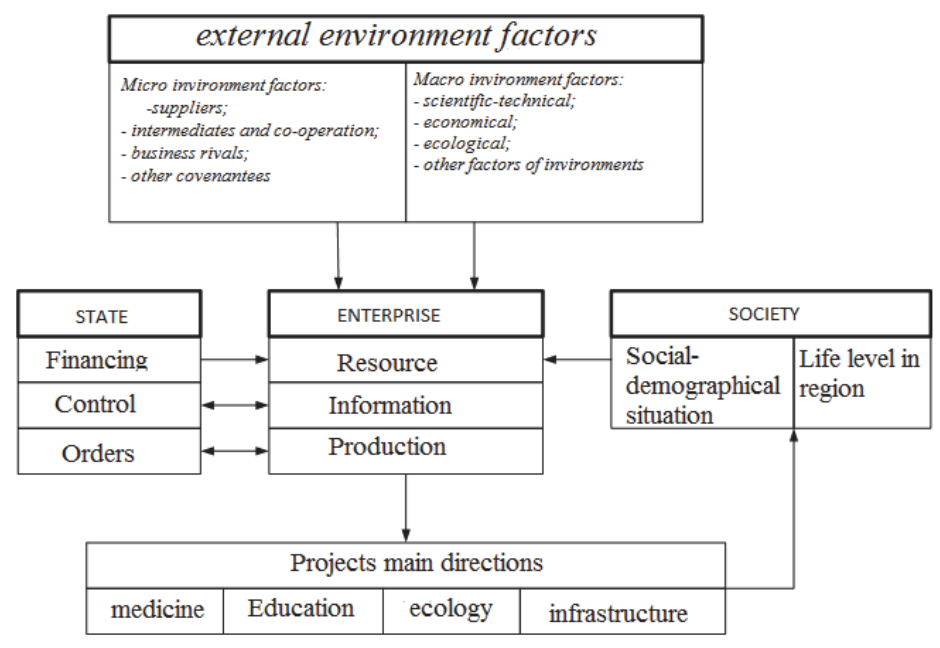

Fig. 1. Scheme of an interrelation of the entities and projects with external environment.

From all variety of external environment factors, exerting influence on enterprises activity, it is possible to carry the following ones to the most significant factors:

- macro environment factors: scientific and technical (have paramount value for high technology production implementation), an economic situation and ecological factors (influence on possible characteristics and projects directions);

- micro environment factors: suppliers (in connection with production features for certain project aspects the circle of suppliers can be limited), intermediates and cooperation with other entities (development and subsequent promotion of the project and socially oriented products in many cases implies collaboration and cooperation with a number of the entities and organizations), competitors.

One of the major interactions is the interrelation with the state. This aspect, first of all, implies an acquisition of number of orders from the state structures in various areas, possible implementation of partial or complete financing of projects and/or of separate developments and execution phase monitoring, to what extent they correspond to plans, standards, regulations, and also accounting of influence on social processes and interactions. It should be noted that a support of innovative socially oriented project activity of the entity can be performed within the following resolutions:

- The Decree of Russian Federation of 4/9/2010 No. 218 «About measures of the state support on cooperation development of Russian higher educational institutions and organizations, implementing the projects complex on creation of high technology production»;

- The Order of the Russian Federation Government of 4/9/2010 No. 219 «About the state support on innovative 
infrastructure development in federal educational institutions of higher education»;

- The order of the Russian Federation Government of 3/30/2009 No. 265 (an edition of 12/28/2010) «About approval of Rules on subsidies provision from the federal budget to organizations of defense industry complex for partial compensation of costs for interest payment on credits received from Russian credit organizations and state corporation "Development bank and foreign economic activity Vnesheconombank" on implementation of innovative and investment projects on release of high-technology products»;

- The order of the Russian Federation Government of 12/31/1999 No. 1460 «About the complex of measures on development and the state support of small enterprises in the sphere of goods production and assistance in their innovative activity».

Also a support can be realized within the Federal law of 7/24/2007 No. 209-FZ «About a development of small and average entrepreneurship in the Russian Federation» (Art. 22).

An interaction with society proceeds within the two main directions. Availability of social component in projects supposes the direct and mediated influence of project implementation results on separate national groups or on social and demographic situation and living level in the region as a whole. In turn, the entity receives a resource provisions within an access to the labor power, markets etc.

The choice of the direction of project implementation becomes the key moment. The main directions of socially oriented projects in high technology production are:

1) medicine: this direction implies a creation of high-technology medical equipment, both: for organizations and for individual use;

2) education: within the education the projects can be realized in two directions - a) creation of equipment, installations, devices, etc. for implementation of educational process; b) participation of students, graduate students in developments and production;

3) ecology: a creation of high-technology products for improvement of ecological situation in the region, an environmental control and assessment;

4) infrastructure: implies a development and creation of products taken a part in infrastructure functioning of the entity, city, region for increase and support of living level of population, improvement of social and demographic situation, and also for increasement of life safety level of society as a whole and of separate individuals.

As we see, the number of developments even within one direction can be rather great, thus a project implementation often bears not just direct, but the mediated effect as well.

The high technology production organization with participation of socially oriented projects will have the features, let's consider on what main issues it is necessary to pay attention at implementation of business processes at the entity.

The projects implementation success depends on group of factors. First of all, it is necessary to consider an industry sign, the project direction, the principles of industrial engineering and already available base of developments. Also a great influence render: the regulatory legal acts, the developed managerial system, structure of the personnel and its qualification, financing of projects, the state participation, an impact of competitors, etc.

In connection to that an interaction of factors groups is rather great, it is necessary to have the integrated controlling mechanism of business processes at the high-technology entity taking into account the projects features. It should consider the management structure available at the entity, an interrelation with macro and micro environment of the company, the possible risks at project implementation, and further as well the perspective of the entity work efficiency evaluation on both: on separately taken project and as a whole for a certain period.

At mechanism drawing up the primary groups of managerial impacts are incorporated into business processes for convenience of display and presentation of interactions. Each business process represents also the finished ring of management (the purpose, planning, organization, realization, control) concerning the specific direction.

Taking into attention the foregoing, regarding as of paramount importance the project targets final adjustment from $\mathrm{R}$ and $\mathrm{D}$ work till production and further product realization, the mechanism will have the following appearance (fig. 2).

For high technology production the projects selection and preparation begins with a stage of $\mathrm{R}$ and $\mathrm{D}$ work consisting of following standard stages (GOST 15.105-2001, 2001; GOST 15.203-2001, 2001):

1) Research: carrying out the researches, development of technical proposal (avanproject); development of specification on experimental development (technological) works;

2) Development: the outline sketch development; engineering design development; working design documentation development on prototype production; prototype production; carrying out the prototype testing; documentation processing; approval of working design documentation for organization of industrial (serial) 
manufacturing of products;

3) Products arrangement for manufacturing and utilization: adjustment of design documentation on revealed latent defects; development of operational documentation.

In R and D work it can be employed their own already available projects developments, and the cooperation with other entities within a part of the project can take place as well, and also the work on special orders of the state or company is possible. After passing of all stages and preparation of necessary documentation the project launches into production.

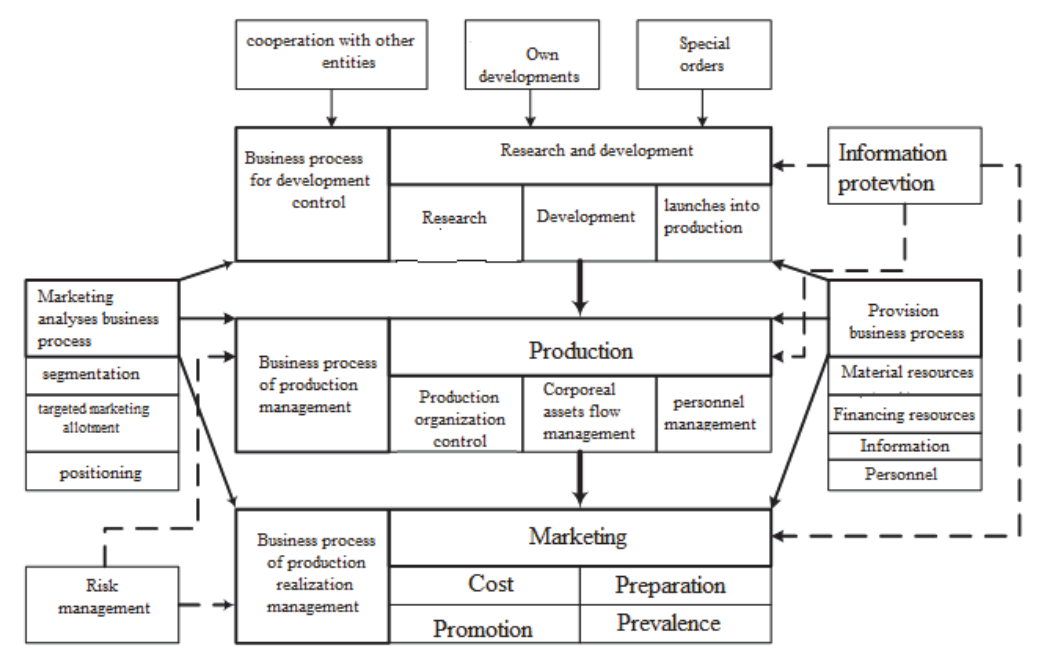

Fig. 2. Scheme of business processes controlling mechanism in high-technology entity.

Production management business process, in addition to accomplishment of the main managerial impacts, regulates the management of production organization, material flows, and also personnel management and labor management as well.

Business process of products sales management considers the production distribution, first of all, as sum-total of four elements - the prices, preparations for sale, distribution channels and goods promotion. However, this business process represents the continuation of one more component - a business process of marketing analysis which is one of the major at the enterprise and it influences on ( $R$ and $D$ work), manufacture and sale in aggregate. Thereby the marketing analysis contains the solution of strategic components: segmentation, allocation of the targeting market and positioning.

The business process of resources provision is directly in charge with support of implementation of all three basic elements [R and D work, development, production, distribution]. This business process includes the following parts: material resources, financial resources, information resources and human resources. The importance and volume of each component vary from an element to element and shall be coordinated with general strategy of company development, distribution according to the projects, taking into account the requirements at this or that stage of realization.

The preparation, development and realization of high-technology project always assumes the availability of large number of confidential information; in this connection there is a need arises in high-quality protection of data at all project lifecycle stages, that is providing the inclusion into mechanism of such block like information protection. This block contains the following basic elements: an object protected data; an object unmasking signs and information leakage technical channels; assessment of possibilities of technical reconnaissance and other sources of threats on information safety; organizational and technical arrangements for information protection; obligations and rights of officials; work planning on protection of information and control; control on condition of information protection; certification of workplaces; interaction with other entities (establishments, organizations) (Standard requirements to the content and order of development of Manual instructions on information protection against technical spy and its leakage per technical channels on the object, 1995).

Due to it the part of risks in the field is considered, the other types of risks concerning production and products distribution are regulated in the mechanism by the block of risk management.

Due to the fact that one of the main tasks in the management of high-tech projects is to manage the relationship 
between time, cost and results, it imposes restrictions as specified by the project itself, and arising during of implementation, generate risks.

Risk management project includes a number of processes that relate to risk management planning, to identify the type of risk, a comprehensive analysis and response to the risks, monitoring and risk management of the project. Most of the above processes are subject to review and updating in the course of project implementation. The main objectives of the risk management of the project - is to increase the likelihood and impact of favorable developments and to reduce the likelihood and impact of adverse events for the project. The risk in the project - is an uncertain event or condition that in case of a positive or negative effect on at least one of the project goals. Thus, the risk may be caused by one or several causes, and in case of occurrence may affect one or more factors.

The occurrence of any of these is not known exactly in advance of events can affect the value of the project, its schedule or performance. It should be noted that the conditions of the risk may also include aspects of the external environment of the organization or project contributes to the risk. This could be, for example, a bad choice methods in project management, lack of common management systems, concurrent execution of multiple projects, or dependency on external participants in the project, which cannot be controlled. The basic cause of the risk is the uncertainty that is present in all projects. Known risks - those risks are identified and analyzed. Such risks may plan a response, but for unknown risk response plan can often be impossible. In such cases, a reasonable solution to the current project is the allocation of the general reserve of various types of resources to unforeseen circumstances, the list of which will be included these unknown risks, as well as all known risks for which the development of specific response is not costeffective or possible.

Risks that pose a threat to the project, can only be taken only if the risk is commensurate benefits that can be obtained by taking this kind of risk. For example, the adoption of the schedule, which may be impaired, the risk is undertaken for the earlier completion of the project. Risks that are opportunities (for example, the acceleration of works by attracting additional staff) may be taken in order to best achieve the objectives of the project. Attitude to risk on the part of individuals and - on a larger scale - organizations due to their understanding of risk and response to the emergence of risk. Where possible, the attitude to risk should be expressed in explicit, measurable form. For each project to be developed consistent approach to the analysis and elaboration of a specific type of risk that meets the requirements of the enterprise, and the information about risk and its management should be open and truthful. The process of respond to risks reflects how the company understands and creates a balance between the adoption of this risk and evasion. To achieve success throughout the project organization should take in advance and consistently precautionary risk management measures. Such an approach can be active, i.e. management personnel seeks to prevent or reduce the impact of risks. But, unfortunately, in most cases on the company expanded a different approach - reactive when problems are solved as they are received, indicating that the lack of elaboration processes of risk management.

For high-tech projects in many cases can be made quantitative risk assessment. Quantitative analysis is performed with respect to those risks in the process of qualitative risk analysis were classified as potentially or significantly affect the properties of competitive products. The main purpose of the analysis - determining the likelihood of achieving the specific objectives of the project, identification of risks requiring special attention, the definition of realistic and achievable goals for cost, schedule or content of the draft risk-based project, finding the best solutions for project management, in the case where some of the conditions remain uncertain. Thus, this analysis provides a quantitative approach to decision-making under uncertainty in project management.

At production management can identify a number of external risks. These include: 1) the external economic risk arises when the company cooperates with foreign firms and fraught mainly with emerging problems with a partner; 2) the risk of volatile market conditions; 3) natural and climatic risks associated with damages incurred due to natural disasters or damage caused to the enterprise environment, which is an additional cost; 4) legal risk affects the internal workflow organization, etc. The internal risks are those that are formed directly in the implementation of the production process in the structural units of the enterprise.

Risks associated with the management of sales of products can be divided into two types. The first type is related to improper marketing assessment and, consequently, the inability to achieve planned sales volume. The second type is linked directly to the process of marketing the finished product, i.e. here include the risks of default, failure of supply, etc.

Thus, one of the major tasks at realization of high-technology projects is the correct forming of managerial impacts that can be realized by means of the special controlling mechanism.

Also, it should be noted that at realization of socially oriented projects, it often can be set the purposes, first of all, directed on achievement of social effect, and then afterwards of commercial benefit. Nevertheless, despite of it would be necessary to consider that the modern high-technology project should be competitive in order to achieve a success, to have high speed of put out into market, and bear in itself a social component as well. 
The research results outlined in this paper were obtained with financial support from Ministry of Education and Science of the Russian Federation, as part of the execution of the project entitled "Establishment of high-tech production for the manufacture of complex reconfigurable systems of high-precision positioning of objects on the basis of satellite systems of navigation, local networks of laser and microwave beacons and technology MEMS", pursuant to decree of the government of the Russian Federation № 218 issued on April 09, 2010. The researches were carried out in SFedU.

\section{References}

European Communities (2008). Science, technology and innovation in Europe. Retrieved from: www.liaison.uoc.gr/documents/sxetikh_ bibliografia/STI_IN_EU_2008.pdf.

Frolov I.E. (2011). Possibilities and problems of modernization of the Russian high-technology complex. Forecasting problems. No. 3. Page 31-55.

GOST 15.105-2001 (2001). «System of development and products delivery to production. Order of accomplishment of research engineering and its components».

GOST 15.203-2001 (2001). «System of development and products delivery to production. An order of development project accomplishment on creation of products and its components».

Standard requirements to the content and order of development of Manual instructions on information protection against technical spy and its leakage per technical channels on the object (1995) (it is approved by the decision of 03.10.95, No. 42 Gostechcomissian of Russia).

Turko D.A. (2013). Analyze of methodical approaches to forming of organizational and economic mechanism of decision taking in high technology production. Magazine «Modern science: actual problems of theory and practice», series «Economy and right» No. 0102.

Washington: NSA (2010). Science and Engineering Indicators 2010. Retrieved from: www.nsf.gov/statistics/digest10/nsb1002.pdf. 